\title{
PENGARUH BUDAYA ORGANISASI, MOTIVASI PELAYANAN UMUM TERHADAP KINERJA PEGAWAI DI STTD
}

\author{
Ir. Bambang Drajat,MM \\ Dosen STTD \\ J1. Raya Setu no.89 \\ Cibuntu - Cibitung \\ Tlp/Fax : ( 021 ) 8254640
}

\author{
Ir. J.R.C Hosang,MT \\ Dosen STTD \\ J1. Raya Setu no.89 \\ Cibuntu - Cibitung \\ Tlp/Fax : ( 021 ) 8254640
}

\author{
Ir. Tonny C.M Korah,M.Si \\ Dosen STTD \\ Jl. Raya Setu no.89 \\ Cibuntu - Cibitung \\ Tlp/Fax : ( 021 ) 8254640
}

\author{
DR. Ir. Djajadi,MM \\ Dosen STTD \\ Jl. Raya Setu no.89 \\ Cibuntu - Cibitung \\ Tlp/Fax : ( 021 ) 8254640
}

\author{
Uriansyah P,MM \\ Dosen STTD \\ Jl. Raya Setu no.89 \\ Cibuntu - Cibitung \\ Tlp/Fax : ( 021 ) 8254640
}

\begin{abstract}
Performance of employees is the work achieved by a person or group of people in accordance with the authority or responsibility of each employee during a certain period. Assessment should provide an accurate picture of employee performance. For this purpose assessment systems should have standards and use reliable measures. The physical condition of the office of the High School of Land Transportation can be said good, where each part has its own room. However, there are still some rooms that are considered less good because the condition of the existing air temperature in some rooms is felt less cool, sometimes even hot. This is due to the air conditioning system that often does not work and not all working rooms have air conditioning system. Similarly, air circulation in some workspaces can be said to be less good, because the air vent is not good. This condition causes a sense of uncomfortable for employees. In addition to the effect on employee performance, organizational culture also has a close relationship with job satisfaction. Job satisfactioncanbedefinedasapleasantorunpleasantemotionalstateinwhichemployeesperceivetheirwor
\end{abstract}

Keywords: Performance of employees, work culture, STTD

\section{ABSTRAKSI}

Kinerja pegawai adalah hasil kerja yang dicapai seseorang atau kelompok orang yang sesuai dengan wewenang atau tanggung jawab masing-masing pegawai selama periode tertentu. Penilaian hendaknya memberikan suatu gambaran akurat mengenai prestasi pegawai. Untuk tujuan ini sistemsistem penilaian harus mempunyai standar dan menggunakan berbagai ukuran yang dapat diandalkan. Kondisi fisik kantor Sekolah Tinggi Transportasi Darat dapat dikatakan baik, dimana setiap bagian memiliki ruangan tersendiri. Akan tetapi masih terdapat beberapa ruangan yang dinilai kurang baik karena kondisi suhu udara yang ada dibeberapa ruangan tersebut dirasakan kurang sejuk, bahkan terkadang terasa panas. Hal ini disebabkan sistem pendingin ruangan yang sering tidak berfungsi dan tidak semua ruangan kerja mempunyai sitem pendingin ruangan. Demikian pula sirkulasi udara dibeberapa ruangan kerja pun dapat dikatakan kurang baik, karena ventilasi udara yang kurang baik. Kondisi ini menimbulkan rasa kurang nyaman bagi para pegawai. Selain berpengaruh terhadap Kinerja pegawai, budaya organisasi juga memiliki keterkaitan yang erat dengan kepuasan kerja. Kepuasan kerja dapat didefinisikan sebagai suatu keadaan emosional yang menyenangkan atau tidak menyenangkan di mana para pegawai memandang pekerjaannya

Kata kunci : Kinerja pegawai, budaya kerja,STTD 


\section{PENDAHULUAN}

Tingkat keberhasilan suatu instansi dapat dilihat dari kinerja instansi mengelola sumber daya yang dimilikinya. Instansi mempunyai kinerja yang baik, mempunyai efektivitas dalam menangani produksi,

Kinerja pegawai adalah hasil kerja yang dicapai seseorang atau kelompok orang yang sesuai dengan wewenang atau tanggung jawab masing-masing pegawai selama periode tertentu. Penilaian hendaknya memberikan suatu gambaran akurat mengenai prestasi pegawai. Untuk tujuan ini sistem-sistem penilaian harus mempunyai standar dan menggunakan berbagai ukuran yang dapat diandalkan.

Kondisi fisik kantor Sekolah Tinggi Transportasi Darat dapat dikatakan baik, dimana setiap bagian memiliki ruangan tersendiri. Akan tetapi masih terdapat beberapa ruangan yang dinilai kurang baik karena kondisi suhu udara yang ada dibeberapa ruangan tersebut dirasakan kurang sejuk, bahkan terkadang terasa panas..

Salah satu faktor eksternal yang mempengaruhi kinerja pegawai adalah budaya organisasi. Budaya organisasi merupakan nilai- nilai yang berkembang dalam suatu organisasi, di mana nilai-nilai tersebut digunakan untuk mengarahkan perilaku anggota-anggota organisasi (Soedjono, 2005).

\section{A. Perumusan Masalah}

Dari latar belakang diatas, masalah dalam penelitian ini sebagai berikut:

1. Apakah terdapat pengaruh Budaya Organisasi terhadap Kinerja pegawai?

2. Apakah terdapat pengaruh dimensi-dimensi Motivasi Pelayanan Publik yang terdiri dari: (a) Ketertarikan terhadap pembuatan kebijakkan publik, (b) Rasa iba, (c) Tanggung jawab terhadap kebutuhan publik, (d) Pengorbanan diri, dan (e) Pemberdayaan, masing-masing berpengaruh terhadap Kinerja pegawai?

\section{METODOLOGI PENELITIAN}

\section{Desain Penelitian}

Tujuan penelitian ini merupakan Testing Hypotesis/ Pengujian Hipotesis. Jenis hubungan antar variabel yang diteliti adalah kausal. Tingkat keterlibatan peneliti dalam penelitian ini adalah moderate/menengah. Setting penelitiannya adalah lingkungan Non Contrived Setting / Inartificial Setting, Unit observasi dalam penelitian ini adalah pegawai Sekolah Tinggi Transportasi Darat, sebanyak 534 pegawai, dimana masing-masing di rinci sebagai berikut: 
Tabel 3.1

Jumlah Pegawai di Unit Kerja Unit Kerja Sekolah Tinggi Transportasi Darat

Tahun 2016/2017

\begin{tabular}{lll}
\hline No. & Unit Kerja & Jumlah pegawai \\
\hline 1 & Rektorat Sekolah Tinggi Transportasi Darat & 103 \\
2 & Jurusan Transportasi Darat - D IV & 41 \\
3 & Jurusan LLAJ - D III & 52 \\
4 & Jurusan Perkeretaapian - D III & 36 \\
5 & Jurusan PKB - D II & 36 \\
\hline & Populasi Total & 267 \\
\hline
\end{tabular}

Sumber: Sekolah Tinggi Transportasi Darat, 2016/2017

Berdasarkan dimensi atau horizon waktu, penelitian ini merupakan penelitian Cross Sectional. Dalam penelitian ini diteliti sebanyak 100 pegawai yang merupakan sampel yang dipilih secara proposional, besarnya masing-masing sampel pada unit kerja Sekolah Tinggi Transportasi Darat sebagai berikut:

Tabel 3.2

Jumlah Sampel Pegawai di Unit Kerja Sekolah Tinggi Transportasi Darat

Tahun 2016/2017

\begin{tabular}{lll}
\hline No. & Unit Kerja & Jumlah pegawai \\
\hline 1 & Rektorat Sekolah Tinggi Transportasi Darat & 37 \\
2 & Jurusan Transportasi Darat - D IV & 15 \\
3 & Jurusan LLAJ - D III & 20 \\
4 & Jurusan Perkeretaapian - D III & 14 \\
5 & Jurusan PKB - D II & 14 \\
\hline & Total Sampel & 100
\end{tabular}

Sumber: Sekolah Tinggi Transportasi Darat, 2015

Dalam penelitian ini diteliti sebanyak 100 orang karyawan sebagai sampel yang dipilih dengan menggunakan teknik Purposive Sampling. Teknik pengambilan sample yang digunakan adalah Purposive sampling yaitu suatu teknik pengambilan sampel dimana sampel yang dipilih berdasarkan kriteria tertentu.

Kriteria sampel yang dipilih adalah: (1) Berstatus pegawai negeri sipil di Sekolah Tinggi Transportasi Darat dan bukan pejabat (staff). (2) Pegawai yang telah bekerja minimal dua tahun.

Berdasarkan hasil pengumpulan data, mayoritas pegawai adalah berjenis kelamin wanita sebesar 59 orang $(59,5 \%)$ dengan usia antara 36 tahun sampai dengan 45,9 
tahun sebanyak 18 orang $(30,25 \%)$, mempunyai pengalaman kerja antara 6 sampai dengan 9,9 tahun sebanyak 18 orang $(30,25 \%)$, mempunyai pendidikan Strata 1 sebanyak 29 orang $(48,74 \%)$, dan mempunyai pangkat antara IIIa hingga IIIc sebanyak 19 orang $(31,93 \%)$, serta mempunyai pendapatan antara 4 juta hingga 5,9 juta rupiah sebanyak 17 orang $(27,73 \%)$.

\section{Analisis Data}

Data dalam penelitian ini dianalisis data dengan mengunakan Univariate dan Multivariate Analysis. Univariate Analysis digunakan untuk mendapatkan hasil Statistik dekriptif, dengan mencari central tendency (Mean) dan Standard Deviasi, sedangkan Multivariate Analysis digunakan untuk pengujian hipotesis. Pengujian hipotesis dilakukan dengan menggunakan metode analisis Structural Equation Modelling (SEM). Sebelum menguji hipotesis diajukan, terlebih dahulu dilakukan analisis full Structural Equation Model sebagai syarat goodness-of-fit model. Berdasarkan Hasil Pengolahan Data, semua kriteria pengukuran mengenai Goodness-of-fit Index dengan nilai yang dapat diterima / cut-off value atau mendekati cut-off value. Hal ini berarti model yang dibangun dapat diterima pada tingkat marginal maupun fit.

Berikut ini fit full structural model penelitian:

Tabel 3.4

\section{Goodness-of-fit Index Full Structural Model}

\begin{tabular}{llll}
\hline Goodness-of-fit & Cut-off Value & Hasil Model & Keterangan \\
\hline Absolute Fit Measure & & & \\
\hline Chi-Square & Diharapkan kecil & $\mathrm{X}^{2}=2607,342$ & Marginal \\
Probability & $\geq 0,50$ & 0,000 & Marginal \\
CMIN/DF & $<2$ & 1,271 & Fit \\
RMSEA & $\leq 0,08$ & 0,037 & Fit \\
\hline NFI & $\geq 0,90$ & 0,743 & Marginal \\
GFI & $\geq 0,90$ & 0,738 & Marginal \\
AGFI & $\geq 0,90$ & 0,717 & Marginal \\
TLI & $\geq 0,95$ & 0,927 & Marginal \\
CFI & $\geq 0,95$ & 0,930 & Marginal \\
\hline Parsimonious fit measures & & & \\
\hline PNFI & $\geq 0,50$ & 0,5786 & Fit \\
PCFI & $\geq 0,50$ & 0,5965 & Fit \\
\hline
\end{tabular}

Sumber: Hasil Pengolahan Data,

Catatan: $C M I N / D F=$ Normed Chi Square; RMSEA $=$ Root Mean Square Error of Approximation; NFI= Normed Fit Index; GFI= Goodness of Fit Index; AGFI= Adjusted Goodness of Fot Index; TLI= Tucker-Lewis I; Pndex; CFI= Comparative Fit Index; PNFI= Parsimony Normed Fit Index; PCFI= Parsimony Comparative Fit Index.

$\mathrm{BCC}=$ Brown-Cudeck Creterion .

\section{Gambar 2 ( Fit Full Structural Model}




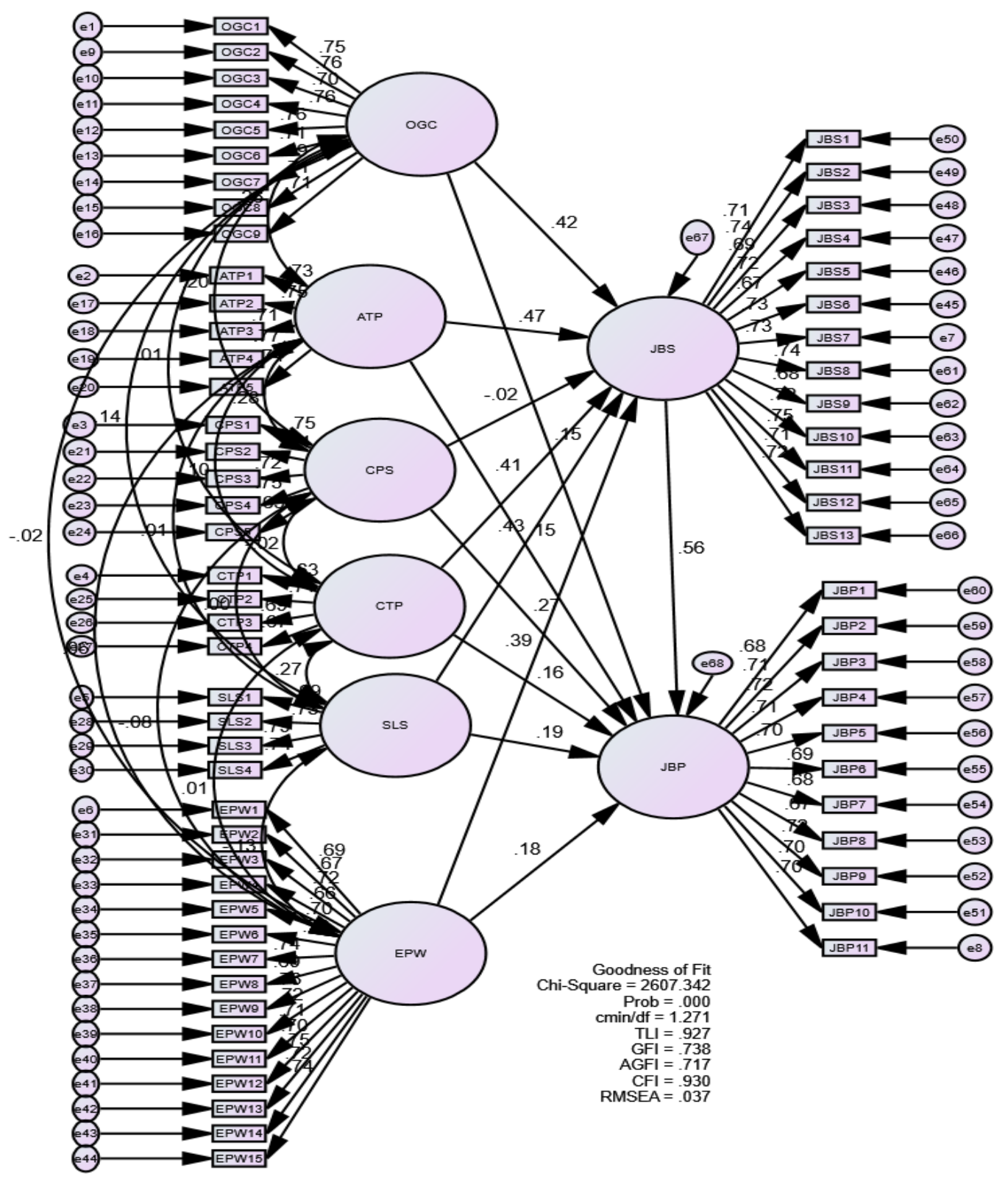

\section{HASIL DAN ANALISIS PENELITIAN}

\section{Statistik Deskriptif Variabel Penelitian}

Analisis statistik deskriptif variabel bertujuan untuk mendapatkan gambaran mengenai respon responden terhadap variabel dan dimensi/indikator penelitian. 
Tabel 4.1

Statistik Deskriptif Variabel Penelitian

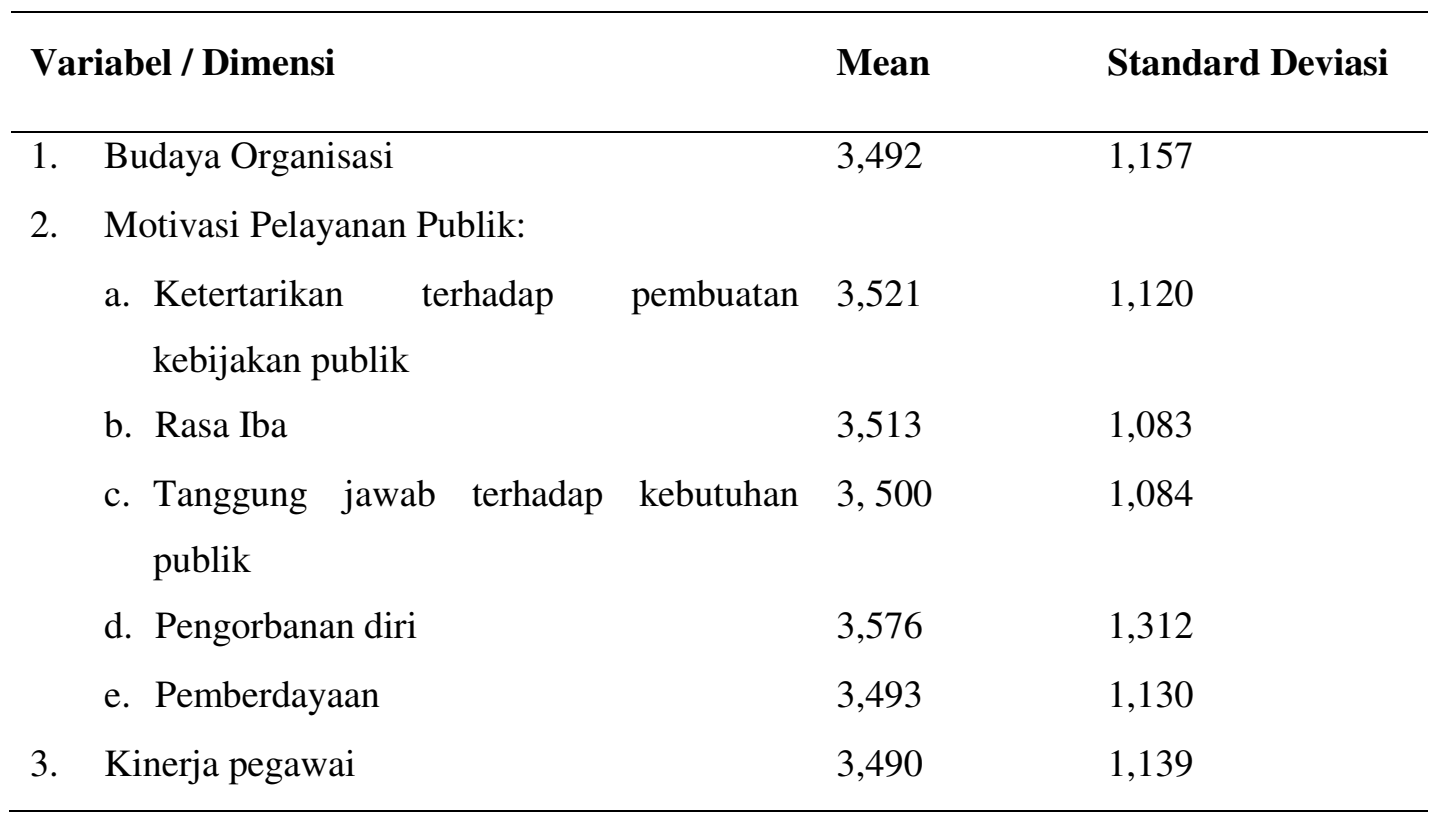

Sumber: Hasil Pengolahan Data

Tabel 4.2

Hasil Pengujian Hipotesis -Outputs Regression Weights

\begin{tabular}{|c|c|c|c|}
\hline Hipotesis & Keterangan & $\begin{array}{l}\text { Standardized } \\
\text { Regression } \\
\text { Weights }(\beta)\end{array}$ & p-Value \\
\hline $\mathrm{H}_{1}$ : & $\begin{array}{l}\text { Terdapat pengaruh positif Budaya } \\
\text { Organisasi terhadap Kinerja pegawai }\end{array}$ & 0,367 & 0,000 \\
\hline $\mathrm{H}_{2 \mathrm{a}}:$ & $\begin{array}{l}\text { Terdapat pengaruh positif Budaya } \\
\text { Organisasi terhadap Ketertarikan terhadap } \\
\text { pembuatan kebijakan publik }\end{array}$ & 0,466 & 0,000 \\
\hline $\mathrm{H}_{2 \mathrm{~b}}$ : & $\begin{array}{l}\text { Terdapat pengaruh positif Budaya } \\
\text { Organisasi terhadap Rasa Iba }\end{array}$ & $-0,021$ & 0,338 \\
\hline $\mathrm{H}_{2 \mathrm{c}}$ : & $\begin{array}{l}\text { Terdapat pengaruh positif Budaya } \\
\text { Organisasi terhadap Tanggung jawab } \\
\text { terhadap kebutuhan publik }\end{array}$ & 0,499 & 0,000 \\
\hline $\mathrm{H}_{2 \mathrm{~d}}$ : & $\begin{array}{l}\text { Terdapat pengaruh positif Budaya } \\
\text { Organisasi terhadap Pengorbanan diri }\end{array}$ & 0,454 & 0,000 \\
\hline $\mathrm{H}_{2 \mathrm{e}}$ : & $\begin{array}{l}\text { Terdapat pengaruh positif Budaya } \\
\text { Organisasi terhadap Pemberdayaan }\end{array}$ & 0,406 & 0,000 \\
\hline $\mathrm{H}_{5 \mathrm{a}}:$ & $\begin{array}{l}\text { Terdapat pengaruh positif Ketertarikan } \\
\text { terhadap pembuatan kebijakan publik }\end{array}$ & 0,146 & 0,000 \\
\hline
\end{tabular}


terhadap Kinerja pegawai

$\begin{array}{llll}\mathrm{H}_{5 \mathrm{~b}}: & \begin{array}{l}\text { Terdapat pengaruh positif Rasa Iba } 0,255 \\ \text { terhadap Kinerja pegawai }\end{array} & 0,000 \\ \mathrm{H}_{5 \mathrm{c}}: & \begin{array}{l}\text { Terdapat pengaruh positif Tanggung } 0,189 \\ \text { jawab terhadap kebutuhan publik terhadap }\end{array} & 0,000 \\ & \text { Kinerja pegawai } & \\ & \text { Terdapat pengaruh positif Pengorbanan } 0,190 \\ & \text { diri terhadap Kinerja pegawai } & 0,000 \\ \mathrm{H}_{5 \mathrm{~d}:} & \text { Terdapat pengaruh positif Pemberdayaan } 0,176 & 0,000 \\ & \text { terhadap Kinerja pegawai } & & \end{array}$

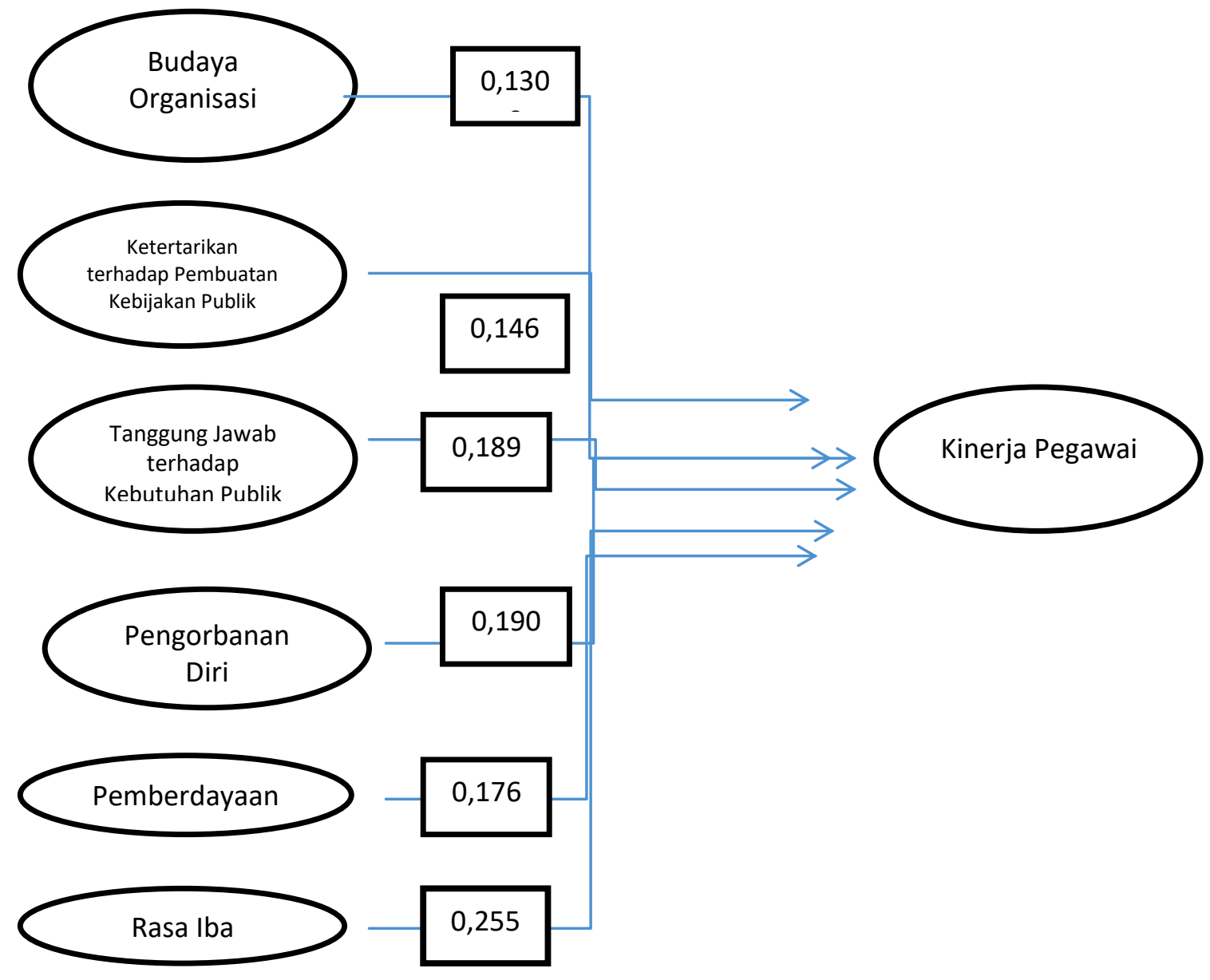


Tabel 4.3

Rangkuman Peran Motivasi Pelayanan Publik dalam Memediasi Hubungan Antar Variabel

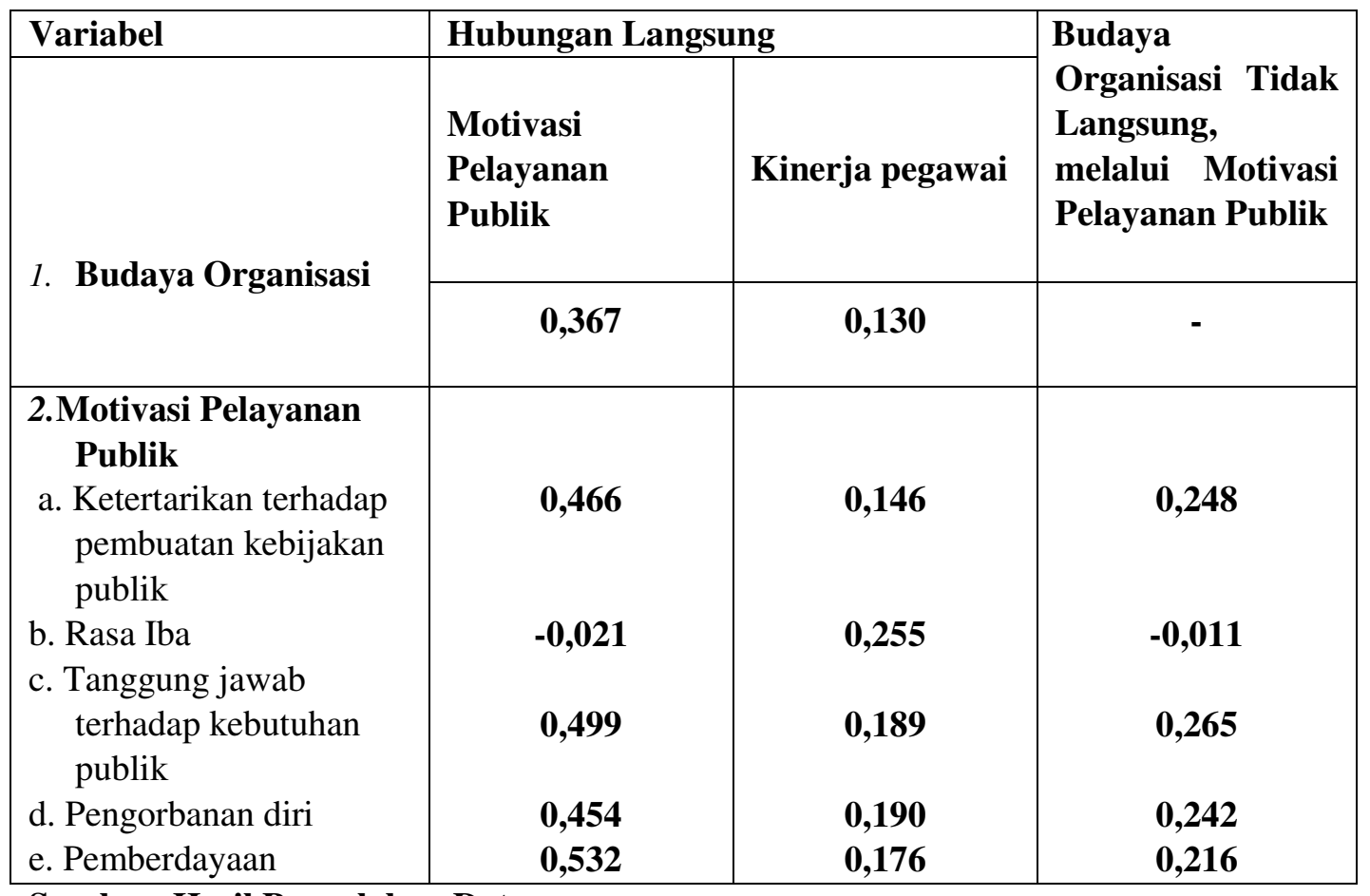

Sumber: Hasil Pengolahan Data

Faktor yang Paling dan Kurang Dominan dalam Membentuk Kontruks Budaya Organisasi, Motivasi Pelayanan Publik dan Kinerja pegawai.

Faktor yang paling dominan dalam membentuk kontruks Budaya Organisasi adalah seluruh pegawai mempunyai semangat berinovasi dan kreatifitas

Faktor yang kurang dominan dalam membentuk kontruks Budaya Organisasi adalah organisasi tempat bekerja mempunyai kebijakan dan SOP yang jelas.

Faktor yang paling dan kurang dominan dalam membentuk Motivasi Pelayanan Publik- Ketertarikan terhadap pembuatan kebijakan publik

Faktor yang paling dominan dalam membentuk kontruks Ketertarikan terhadap pembuatan kebijakan publik adalah apabila pegawai memberikan pelayanan yang terbaik untuk masyarakat.

Faktor yang kurang dominan dalam membentuk kontruks Ketertarikan terhadap pembuatan kebijakan publik adalah apabila pegawai rela mengorbankan tenaga untuk melayani masyarakat

Faktor yang paling dan kurang dominan dalam membentuk Motivasi Pelayanan Publik- Rasa Iba

Faktor yang paling dominan dalam membentuk kontruks Rasa Iba adalah apabila pegawai merasa melayani masyarakat adalah sesuatu yang bermakna 
Faktor yang kurang dominan dalam membentuk kontruks Rasa Iba menghargai pegawai yang melayani masyarakat dengan mengikuti aturan-aturan yang jelas.

Faktor yang paling dan kurang dominan dalam membentuk Motivasi Pelayanan Publik- Tanggung jawab terhadap kebutuhan publik

Faktor yang paling dominan dalam membentuk kontruks Tanggung jawab terhadap kebutuhan publik adalah pegawai yang selalu mencari cara-cara yang kreatif dalam melayani masyarakat agar puas.

Faktor yang kurang dominan dalam membentuk kontruks Tanggung jawab terhadap kebutuhan publik adalah pegawai dalam bekerja merasa dalam melayani masyarakat membutuhkan dukungan.

Faktor yang paling dan kurang dominan dalam membentuk Motivasi Pelayanan Publik- Pengorbanan diri

Faktor yang paling dominan dalam membentuk kontruks Pengorbanan diri adalah pegawai yang tidak terlalu memperhatikan orang-orang berpolitik.

Faktor yang kurang dominan dalam membentuk kontruks Pengorbanan diri adalah pegawai dalam melayani masyarakat tidak melibatkan politik.

Faktor yang paling dan kurang dominan dalam membentuk Motivasi Pelayanan Publik- Pemberdayaan

Faktor yang paling dominan dalam membentuk kontruks Pemberdayaan adalah pegawai yang yakin akan kemampuan untuk mengerjakan pekerjaan.Faktor yang kurang dominan dalam membentuk kontruks Pemberdayaan adalah pegawai yang berarti dengan aktivitas bekerja secara pribadi.

Kesimpulan: adalah faktor yang paling dominan dalam membentuk kontruks Motivasi Pelayanan Publik adalah Pemberdayaan. Faktor yang kurang dominan dalam membentuk kontruks Motivasi Pelayanan Publik adalah Tanggung jawab terhadap kebutuhan public

\section{Faktor yang paling dan kurang dominan dalam membentuk Kinerja pegawai}

Faktor yang paling dominan dalam membentuk kontruks Kinerja pegawai adalah pegawai mempunyai kualitas melebihi standar yang ditetapkan, sedangkan faktor yang kurang dominan dalam membentuk kontruks Kinerja pegawai adalah pegawai memiliki kemampuan yang tinggi dalam melaksanakan pekerjaan.

\section{Variabel yang Paling dan Kurang Kuat Dalam Mempengaruhi Budaya Organisasi, Kepuasan Kerja dan Kinerja pegawai}

Setelah menganalis indikator yang paling kuat yang membentuk masing-masing variabel Motivasi Pelayanan Publik, Kepuasan Kerja, dan Kinerja pegawai Sekolah Tinggi Transportasi Darat, maka selanjutnya akan dianalisis variabel yang paling dan kurang kuat mempengaruhi Kepuasan Kerja dan Kinerja pegawai. Dibawah ini dapat dilihat pengaruh Dimensi-dimensi Budaya Organisasi dan Motivasi Pelayanan Publik (Ketertarikan terhadap pembuatan kebijakkan publik, Rasa iba, Tanggung jawab 


\section{SIMPULAN}

Simpulan penelitian yang diperoleh berdasarkan hasil analisis data dan pembahasan, sebagai berikut: Penelitian ini dilakukan pada Sekolah Tinggi Transportasi Darat. Data yang dikumpulkan dari sebagian pegawai Sekolah Tinggi Transportasi Darat, dapat diketahui bahwa mayoritas pegawai adalah berjenis kelamin wanita, berusia 36 tahun sampai dengan 45,9 tahun, mempunyai pengalaman kerja 6 sampai dengan 9,9 tahun, mempunyai pendidikan Strata 1, dan mempunyai golongan IIIa hingga IIIc, serta mempunyai pendapatan 4 juta rupiah hingga 5,9 juta rupiah.

Adapun tujuan penelitian yang hendak dicapai adalah untuk menganalisis faktor-faktor yang mempengaruhi Kinerja pegawai pada Sekolah Tinggi Transportasi Darat. Faktor-faktor tersebut adalah Budaya Organisasi, dan Motivasi Pelayanan Publik

1. Berdasarkan data yang di kumpulkan pada masing-masing variabel dapat diperoleh gambaran bahwa: (a) Budaya Organisasi pada Sekolah Tinggi Transportasi Darat telah berjalan baik, (b) Pegawai telah mempunyai motivasi yang tinggi untuk memberikan pelayanan kepada masyarakat (Motivasi Pelayanan Publik). Pegawai telah merasakan kepuasan dalam bekerja, disebabkan karena pekerjaan yang dilakukannya mempunyai metode dan kebijakan yang jelas untuk karier, atasan menunjang dan mampu mengambil keputusan, adanya jalur promosi yang jelas. (d) Pegawai sudah memiliki kinerja yang baik.

2. Dari 19 Hipotesis yang diuji, diperoleh hasil bahwa seluruh Hipotesis didukung, kecuali 2 Hipotesis yang tidak didukung, yaitu tidak terdapat pengaruh positif: (a) Rasa iba terhadap Kepuasan Kerja, dan (b) Rasa iba terhadap Kinerja Pegawai melalui Kepuasan Kerja.

3. Penelitian yang dilakukan juga menemukan bahwa Kepuasan Kerja berperan dalam memediasi hubungan antara Budaya Organisasi dengan Kinerja Pegawai. Disamping itu, Kepuasan Kerja berperan pula dalam memediasi hubungan antara seluruh dimensi-dimensi Motivasi Pelayanan Publik (Ketertarikan terhadap pembuatan kebijakan publik, Tanggung jawab terhadap kebutuhan publik, Pengorbanan diri, dan Pemberdayaan) dengan Kinerja Pegawai, kecuali Rasa iba.

4. Penelitian yang dilakukan juga menemukan bahwa Kepuasan Kerja berperan dalam memediasi hubungan antara Budaya Organisasi dengan Kinerja Pegawai. Disamping itu, Kepuasan Kerja berperan pula dalam memediasi hubungan antara seluruh dimensi-dimensi Motivasi Pelayanan Publik (Ketertarikan terhadap pembuatan kebijakan publik, Tanggung jawab terhadap kebutuhan publik, Pengorbanan diri, dan Pemberdayaan) dengan Kinerja Pegawai, kecuali Rasa iba.

\section{Implikasi Teoritis dan Implikasi Manajerial}

\section{Implikasi Teoritis}


Berdasarkan hasil penelitian yang dilakukan, terdapat beberapa hal yang penting yang dapat memberikan kontribusi teori yang dapat bermanfaat bagi pengembangan ilmu pengetahuan, yaitu:

1. Pemberdayaan yang ditambahkan sebagai dimensi baru dalam Motivasi Pelayanan Publik merupakan faktor yang perlu dipertimbangkan dalam melakukan Motivasi Pelayanan Publik pada Sekolah Tinggi Transportasi Darat.

2. Dari hasil penelitian tidak ditemukan adanya pengaruh positif Rasa iba terhadap Kepuasan Kerja, berdasarkan temuan tersebut maka model baru yang dapat diusulkan untuk Sekolah Tinggi Transportasi Darat dalam meningkatkan Kinerja Pegawai dapat dilihat pada Gambar 5.1 dibawah ini.

3. Oleh karena itu dapat diusulkan bahwa dimensi dari Motivasi Pelayanan Publik bagi Sekolah Tinggi Transportasi Darat adalah (1) Ketertarikan terhadap pembuatan kebijakan publik terhadap Kinerja Pegawai, (2) Tanggung jawab terhadap kebutuhan publik, (3) Pengorbanan diri, (4) Pemberdayaan.

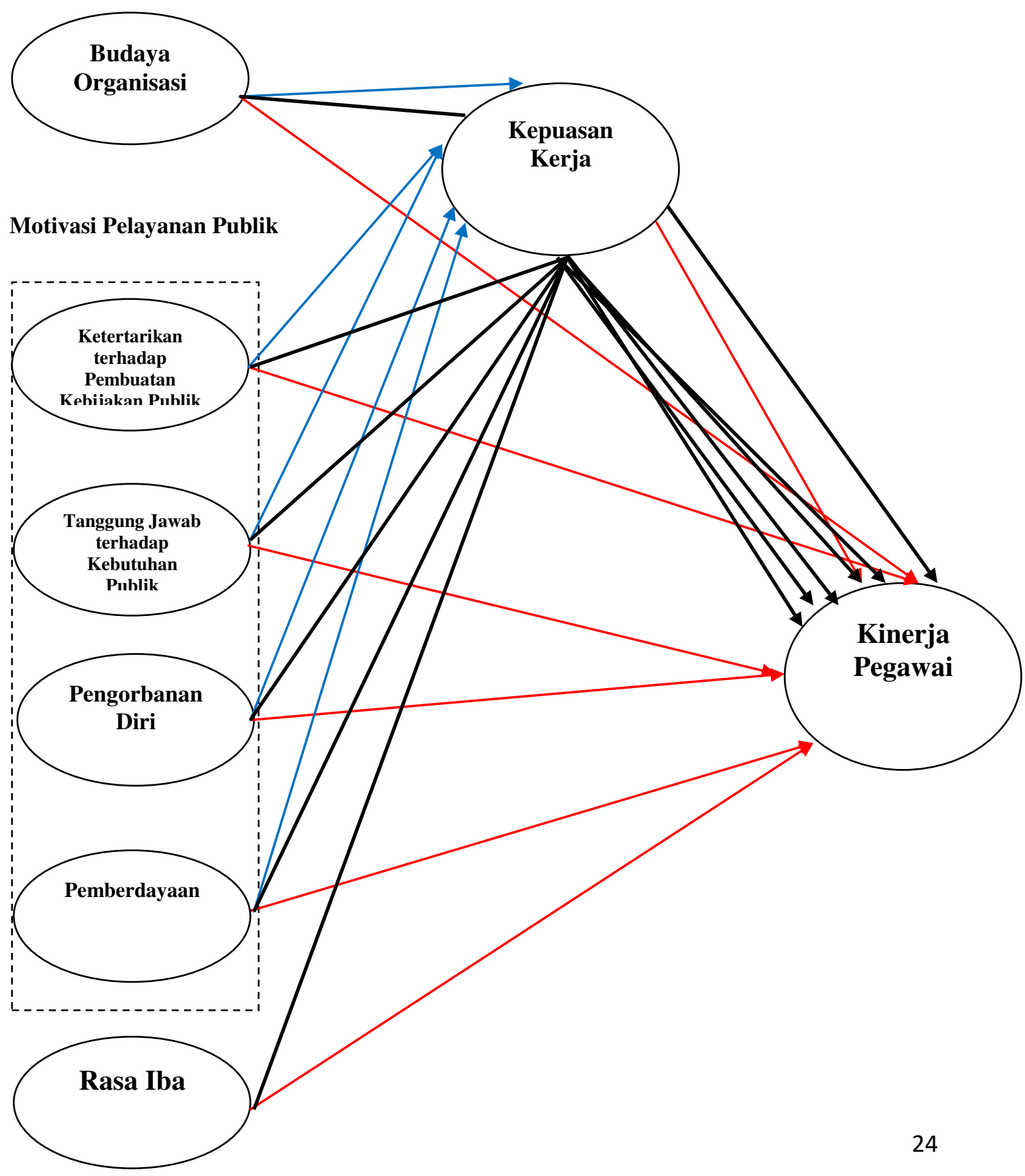




\section{Implikasi Manajerial}

Beberapa saran yang dapat diberikan kepada Ketua Sekolah Tinggi Transportasi Darat untuk meningkatkan Kinerja Pegawai adalah dengan meningkatkan Budaya Organisasi dan Motivasi Pelayanan Publik (Ketertarikan terhadap pembuatan kebijakan publik, Tanggung jawab terhadap kebutuhan publik, Pengorbanan diri, Pemberdayaan), dan Kepuasan Kerja.

1) Untuk meningkatkan Budaya Organisasi disarankan agar Ketua Sekolah Tinggi Transportasi Darat perlu melakukan upaya untuk memperkuat dan mempertahankan Budaya Organisasi yang sudah ada guna meningkatkan Kinerja Pegawai dengan cara:

a) Mengadakan sosialisasi lebih mendalam mengenai visi, misi, nilai-nilai, serta peraturan-peraturan yang berlaku dalam perusahaan agar pegawai mampu memahami tugas dan tanggung jawab mereka sehingga dalam implementasinya dapat berjalan dengan baik sesuai dengan arah dan tujuan perusahaan.

b) Melibatkan pegawai dalam setiap kegiatan perusahaan agar terbangun kerja sama yang baik dan rasa saling menghargai antar para pegawai maupun pegawai dengan atasan.

c) Memberikan kesempatan bagi setiap pegawai untuk berinteraksi guna membangun rasa saling percaya dan keterbukaan antar sesama pegawai maupun pegawai dengan atasan.

2) Untuk meningkatkan Motivasi Pelayanan Publik disarankan agar Ketua Sekolah Tinggi Transportasi Darat perlu melakukan upaya untuk memperkuat dan mempertahankan Motivasi Pelayanan Publik yang sudah ada guna meningkatkan Kinerja Pegawai dengan cara:

a) Ketertarikan terhadap pembuatan kebijakan publik, selalu menekankan untuk bersedia setiap saat untuk melayani masyarakat, memberikan semboyan untuk dapat melayani masyarakat kepada seluruh pegawai, dan memberikan dorongan kepada pegawai untuk dapat berkontribusi di masyarakat.

b) Rasa iba, selalu memberikan penghargaan kepada pegawai yang melaksanakan tugasnya dengan baik, selalu mengingatkan pegawai agar mempunyai etika dalam melayani masyarakat, dan mengambil tindakan jika ada pegawai yang tidak memberikan pelayanan kepada masyarakat secara baik.

c) Tanggung jawab terhadap kebutuhan publik, memberikan dukungan kepada pegawai dalam melayani masyarakat.

d) Pengorbanan diri, selalu mengingatkan kepada pegawai untuk tidak mengikuti politik/partai, dan kebijakan yang diberikan tidak merugikan/mengganggu kepentingan pegawai.

e) Pemberdayaan, selalu menekankan bahwa pekerjaan yang dilakukan sangat berarti bagai pegawai, memperkenalkan metode-metode baru untuk memperbaiki kelompok kerja pegawai 


\section{Rekomendasi Untuk Penelitian Selanjutnya}

Beberapa saran yang dapat diberikan untuk penelitian selanjutnya adalah sebagai berikut;

Pertama, disarankan untuk menerapkan dan mengkaji model determinan Kinerja pegawai yang diusulkan untuk Sekolah Tinggi Lainnya di Lingkungan Badan Pendidikan SDM Perhubungan (STIP dan STPI).

Kedua, disarankan untuk menambah dimensi Gender dari variabel Motivasi Pelayanan Publikke dalam model (DeHart-Davis et al., 2006).

Ketiga, disarankan untuk memasukkan variable Komitmen Organisasi sebagai determinan Kinerja pegawai (Meyer et. al., 1989).

\section{DAFTAR PUSTAKA}

Abd-El-Slam, E.M., Shawky, A.Y., Nawar, Y.S. (2013). The Relationship among job Satiffaction, Motivation, Leadership, Communication, and Psychological Empowerment: An Egyptian Case Study. SAM Advanced Management Journal, 78(2), 33-50.

Abdulla, J., Djebarni, R., Mellahi, K. (2011). Determinants of job satisfaction in the UAE. Personnel Review, 40(11), 126-146.

Abdulloh, (2006). Pengaruh Budaya Organisasi, Locus of control, dan Kepuasan kerja terhadap kinerja karyawan pada kantor pelayanan pajak semarang barat, Tesis, Semarang: Universitas Diponegoro

Ahmad, K.H., Veerapandian, K., Ghee, W.Y. (2011). Person-environtment fit: the missing link in the organizational culture-commitment relationship. International Journal of Business and Management, 6(11), 11-20.

Aida (2008). Motivasi, Kepuasan dan Produktivitas Kerja Penyuluh Lapangan Peternakan. Jurnal Media Peternakan, 31(1), 71-80.

Akbar, Dimas R. (2014). Pengaruh kemampuan, public service motivation dan job satisfaction terhadap performance pegawai negeri sipil di lingkungan kecamatan tambaksari Surabaya. Kebijakan dan Manajemen Publik, 2(1).

Alonso, P. and Lewis, G.B (2001), Public service motivation and job performance: evidence from the federal sector, American Review of Public Administration, 31(2), 363-81.

Anggraeni and Nenny (2011). Pengaruh kemampuan dan public service motivation terhadap performance pegawai pada sekolah tinggi seni Indonesia (STSI) Bandung. Jurnal Penelitian Pendidikan. 1-20. 
